\title{
OS SÍTIOS SIMBÓLICOS DE PERTENCIMENTO DOS COLONOS E DOS CABOCLOS DO OESTE DE SANTA CATARINA*
}

\author{
Clóvis Dorigon**
}

Arlene Renk***

\begin{abstract}
Resumo
Tendo como ponto de partida os hábitos alimentares regionais e os contextos em que tais alimentos são produzidos e consumidos, busca-se neste texto problematizar a abordagem teórica dos sítios simbólicos de pertencimento, ainda de pouca circulação no Brasil. A partir de dados empíricos relacionados aos hábitos alimentares e das festividades organizadas em torno do consumo de alimentos originários do saber-fazer dos agricultores, analisa-se a presença na região oeste de Santa Catarina de dois Sítios Simbólicos de Pertencimento. Um deles formado pelos descendentes de imigrantes europeus (italianos, alemães e poloneses). O outro pelos caboclos, população preexistente à chegada dos colonos. Os caboclos foram excluídos de suas terras para dar lugar àqueles. Estabelecem-se comparações entre a noção de Sítio com outras noções, em especial com a de habitus de Bourdieu e a de economia substantiva de Karl Polanyi. Dentre as conclusões, sublinha-se que a noção de sítios simbólicos de pertencimento oferece recursos ao estudar o homo situs como animal territorial. No caso analisado, tem-se um território partilhado com duas territorialidades, marcadas por processos históricos distintos, a inclusão pela colonização, para um grupo e a exclusão para outro grupo. A escolha do idioma da comida como fio condutor permitiu traçar o homo situs apontando as peculiaridades, a processualidade e os desdobramentos dos entrecruzamentos das histórias.
\end{abstract}

Palavras-chave: Sítio simbólico de pertencimento. Antropologia da alimentação. Produtos coloniais. Comida cabocla.

\footnotetext{
* O presente trabalho foi realizado com o apoio financeiro da Fundação de Amparo à Pesquisa e Inovação do Estado de Santa Catarina (FAPESC). Uma versão preliminar deste artigo foi apresentada no VI Encontro Nacional de Estudos do Consumo (VI ENEC).

** Graduado em Agronomia pela Universidade Federal de Santa Catarina (UFSC) - 1986, mestre em Desenvolvimento, Agricultura e Sociedade pela Universidade Federal Rural do Rio de Janeiro (UFFRJ) - 1997, doutor em Engenharia de Produção pela Universidade Federal do Rio de Janeiro (UFRJ/Coppe) - 2008, com período sanduíche pela École des Hautes Études en Sciences Sociales (EHESS) de Paris. Pesquisador da Empresa de Pesquisa Agropecuária e Extensão Rural de Santa Catarina (Epagri)/Centro de Pesquisa para a Agricultura Familiar (Cepaf). Chapecó - Santa Catarina - Brasil. E-mail: cdorigon@epagri.sc.gov.br

*** Mestre e doutora em Antropologia pelo Museu Naciona1/Universidade Federal do Rio de Janeiro (UFRJ), professora dos Programas de Pós-Graduação stricto sensu em Ciências Ambientais e Direito da Universidade Comunitária da Região de Chapecó (Unochapecó). Chapecó - Santa Catarina - Brasil.E-mail: arlene@unochpapeco.edu.br
} 


\section{Introdução}

Tendo como ponto de partida os hábitos alimentares regionais e os contextos em que tais alimentos são produzidos e consumidos, buscase neste texto problematizar a abordagem teórica/categoria dos sítios simbólicos de pertencimento, ainda de pouca circulação no Brasil.

Este texto parte das análises de Renk (1996, 1997, 2000), Renk e Savoldi (2008), Dorigon (2008), às quais são incorporados os resultados da pesquisa "Inventário dos produtos coloniais e de seus processos tradicionais de produção na região oeste de Santa Catarina”(DORIGON; RENK, 2011, 2013; DORIGON et al., 2015) ${ }^{1}$. Esta última teve por objetivo resgatar e sistematizar o conjunto de conhecimentos tradicionais que fazem parte do patrimônio cultural das populações rurais da referida região.

A partir de dados empíricos relacionados aos hábitos alimentares e das festividades organizadas em torno do consumo de alimentos originários do saber-fazer dos agricultores, analisa-se a presença na região oeste de Santa Catarina de dois sítios simbólicos de pertencimento. Um deles é aquele formado pelos colonos, descendentes de imigrantes italianos, alemães e poloneses. A região possui características que lhe imprimem uma identidade própria, singularidades que a diferenciam de outras regiões do País, por exemplo, o predomínio da agricultura familiar, o seu processo de colonização, os sistemas de produção, a estrutura produtiva e agrária, a forte presença de indústrias agroalimentares, de instituições e movimentos sociais, dentre outras (DORIGON, 2008). Este caracterizaria o sítio simbólico de pertencimento ligado aos descendentes de europeus, do qual os produtos coloniais (queijos, embutidos de carne suína, panificados, doces, geleias e derivados da canade-açúcar, entre outros) são uma de suas expressões, pois são portadores de valores, saberes e experiências vividas e compartilhadas. Em muitos casos, trata-se de processo que Hobsbawm e Ranger (1984) nominam por invenção das tradições, em face das modificações de ingredientes em razão de não encontrar os originais utilizados na Europa, das alterações do modo de fazer e de outros procedimentos introduzidos ao longo do tempo, mas sempre remetido a um tempo iniciado do qual se origina.

O outro sítio seria formado pelos caboclos - grupo autóctone local anterior à colonização. Os caboclos foram excluídos de suas terras para dar lugar aos colonos. Trata-se, portanto, de população mais empobrecida e excluída socialmente e ator social protagonista de uma das maiores guerras camponesas da história, a Guerra do Contestado ou fugitivos da Revolução Federalista do Rio Grande do Sul.

Assim, por intermédio da narrativa alimentar (produção e consumo de alimentos artesanais), problematiza-se a noção de Sítio. Parte-se de dados empíricos, mas busca-se a discussão teórica. Há um diálogo entre a
1 Pesquisa financiada pela "Chamada Pública Pesquisa Científica, Tecnológica e Inovação em Ciências Agrárias - FAPESC 08/2009". 
noção de Sítio e outras noções, em especial com a de habitus de Bourdieu (1979), Bourdieu e Sayad (1964) a e a economia substantiva de Karl Polanyi (1980).

\section{A noção de sítio simbólico de pertencimento}

A teoria dos sítios simbólicos de pertencimento tem como seu principal autor Hassan Zaoual (2003, 2006a, 2006b) em colaboração com Latouche (1999) e Panhuys (2006), dentre outros. A noção de sítios simbólicos de pertencimento foi formulada a partir de uma crítica radical aos modelos de desenvolvimento impostos pelos países ricos aos demais, a partir da denúncia da falência dos modelos de "desenvolvimento transposto" em que o livre mercado se impõe sobre as demais dimensões da vida humana, tais como as diferentes culturas, a diversidade e o respeito ao meio ambiente (DORIGON, 2008).

Zaoual propõe não somente uma mudança profunda em direção a novos valores como também a promoção de uma economia plural, integrando a intervenção pública, o setor das organizações de economia social e solidária e uma parte do mercado. A articulação dessas várias dimensões da vida social deveria ocorrer concomitantemente com a implicação dos cidadãos no quadro de seu território local. Zaoual (2003) argumenta que estas propostas encontram atualmente condições favoráveis devido ao recente êxito de iniciativas de descentralização, de governança e de desenvolvimento local nos próprios países onde a globalização tem suas origens e seu motor.

Segundo Zaoual (2003), o fracasso do desenvolvimento nos países do Sul e as incertezas das economias de mercado nos países do Norte geram confusão no modo de representar o mundo e de nele agir. As tensões e recomposições seriam a raiz da afirmação das identidades e dos territórios. Assim, em todos os lugares, cada vez mais, as pessoas sentiriam a necessidade de se inserir em locais de pertencimento:

$\mathrm{Na}$ medida em que cresce o global, também se amplia o sentimento do local. As razões deste paradoxo são múltiplas, entre as quais mencionamos a seguinte: a globalização, sinônimo de mercantilização do mundo, introduz localmente um tipo de incerteza e de vertigem na mente humana. Uma das maneiras de reagir a isso consiste na busca da certeza de que somente a proximidade pode garantir, até certo ponto, o sentimento de pertencer. (ZAOUAL, 2003, p. 21).

Para se contrapor ao que denomina de "economia da violência", Zaoual (2003) enfatiza a potência dos contextos de atuação dos atores e o enraizamento da economia nas crenças e nas microssociedades locais. Em contraposição ao homo oeconomicus, resultado do discurso da globalização, 
Zaoual propõe o conceito de homo situs, sob o argumento de que os homens nunca reagem de maneira idêntica em todos os lugares, pois suas racionalidades se constroem socialmente em um determinado lugar - “in situ". Essas racionalidades situadas seriam diversas, compósitas, flexíveis, complexas e abertas.

Essa concepção do humano e do social abre a perspectiva para Zaoual (2006a) formular seu conceito de "sítio simbólico de pertencimento", definido como:

De modo essencial, cada sítio é uma entidade imaterial que impregna o conjunto da vida em dado meio. Ele possui um tipo de caixa preta feita de crenças, mitos, valores e experiências passadas, conscientes ou inconscientes, ritualizadas. Ao lado deste aspecto feito de mitos e ritos, o sítio possui também uma caixa conceitual que contém seus conhecimentos empíricos e/ou teóricos, de fato, um saber social acumulado durante sua trajetória. Enfim, os atores em dada situação operam com sua caixa de ferramentas que contém seu saber-fazer, técnicas e modelos de ação próprios ao contexto. (ZAOUAL, 2006a, p. 32).

Sinteticamente, o sítio simbólico de pertencimento pode ser entendido como um marcador imaginário de espaço vivido. Ou seja, tratase, de acordo com Zaoual (2003), de uma entidade imaterial (ou intangível) que impregna o conjunto do universo local dos atores. Em oposição ao culturalismo, o estudo dos sítios (sitologie) é uma abordagem não estática, em que sua definição busca incorporar, além de visão dinâmica, a percepção da complexidade e da mestiçagem cultural. Opõe-se, portanto, ao economicismo, na medida em que nenhuma dimensão da existência humana pode estar separada das outras. Assim, “[...] crenças, conceitos e comportamentos se articulam em torno de um sentido de pertencimento e criam forte relatividade das leis econômicas no mesmo momento em que o mundo parece uniformizar-se" (ZAOUAL, 2003, p. 28). Dessa forma, o autor propõe o fim da hegemonia de um só e único ponto de vista, de um único modelo para todos, apontando para a incapacidade das instituições do mercado reger todas as dimensões da vida humana.

A abordagem teórica dos sítios simbólicos de pertencimento representa uma ferramenta de análise que permite integrar a identidade regional à noção de território e de cultura, dos quais a economia de uma determinada região é resultado (DORIGON, 2008). Zaoual (2003) desenvolve também uma crítica à ciência ocidental, em especial à ciência econômica, a qual está no comando da civilização global:

Abstrata, dedutiva, e dividida em especializações estanques, ela empurra a humanidade em direção a um desastre social e ambiental. Apesar dos sucessivos fracassos econômicos transpostos nos países 
do Sul e, também, do esgotamento do mito do progresso nos países mais adiantados na aventura do desenvolvimento, as crenças científicas vinculadas a essa ciência estão resistindo à necessidade de uma mudança profunda. (ZAOUAL, 2003, p. 18).

Estas singularidades podem ser mais bem compreendidas ao se adotar a perspectiva proposta por Zaoual (2006a) no que diz respeito à necessidade de uma civilização da diversidade que, por sua vez, está enraizada em um determinado território:

Torna-se lógico que a escala mais pertinente seja a do território. Enquanto espaço simbólico e cognitivo, o sítio magnetiza os comportamentos e marca profundamente os códigos, as normas, as convenções, as instituições locais e, finalmente, o meio local circundante. Tal como a mão invisível do mercado o sítio é uma estrutura imaginária de coordenação econômica e social, mas ele associa instantaneamente as duas dimensões, contrariamente ao mercado. Assim, toda governança deve se abrir ao sítio e adotar suas singularidades (cultura, valores e instituições). (ZAOUAL, 2006a, p. 18).

Segundo Zaoual (2003, p. 54), o homem é um “animal territorial”. Esse vínculo imaginário "[...] é quase instintivo. Para viver e decidir seu comportamento, a necessidade de crer e de estar motivado e de agir é inerente à condição humana. A inovação, a criatividade, o desempenho econômico dependem disso".

O conceito de sítio, segundo Zaoual (2003), pode ser aplicado a múltiplas escalas e organizações, como um bairro, uma cidade, uma região, uma localidade, uma etnia, um país, uma cultura. Assim, para a aplicação da noção de sítio, é preciso situá-la empiricamente, definindo a escala a ser adotada (DORIGON, 2008).

Partindo-se da noção de sítio simbólico de pertencimento, e tomando-se como narrativa as comidas, argumenta-se que na região oeste existem pelo menos dois sítios simbólicos de pertencimento ainda com contornos bastante claros: o sítio dos colonizadores e o dos caboclos.

A seguir buscamos avançar na discussão teórica e justificar com dados empíricos a existência destes dois sítios, narrando suas tradições alimentares, tanto do consumo cotidiano como em eventos festivos ou religiosos.

\section{Os sítios simbólicos de pertencimento dos colonos e dos caboclos do oeste de Santa Catarina}

Neste ensaio, nós nos debruçamos historicamente em dois movimentos de deslocamentos populacionais. Um deles pode ser nominado por enxamagem, como quer o geógrafo Jean Roche (1969), quando os 
europeus, os de origem, deixaram a Europa, em um processo de imigração para colonização e com os posteriores deslocamentos internos no país.

Ao se analisar a imigração italiana para o Brasil, segundo Martins (2003), o interesse forte pelos elementos factuais colocou em segundo plano o que, segundo o autor, talvez tenha sido seu aspecto mais importante, o imaginário:

Representa muito sair da própria pátria, do calor afetivo da família extensa na aldeia de origem, do riso acolhedor dos compadres e amigos na osteria, de costumes arraigados seculares, de certezas definitivas, e lançar-se na aventura e emigrar para um país distante e desconhecido. Busca. Mas muitas perdas, muitos dilaceramentos, muitas incertezas nesse adeus quase sempre definitivo, na viagem difícil em que nada se podia ver além da linha do horizonte do oceano imenso. (MARTINS, 2003, p. 17).

E esse imaginário se fazia presente, também, entre os imigrantes que vieram para o Sul do Brasil, em sua absoluta maioria, em busca de terras, como estratégia de reprodução social camponesa, movidos pela esperança de encontrar a Cocanha, entre os italianos, ou a Schlarafenland, seu equivalente em alemão, isto é, o sonho medieval de fartura em alimentos e de vida amena (FRANCO, 1998). Uma fração desses indivíduos desembarcou em terras sul rio-grandenses. As terras e as comidas encontradas estavam longe dos sonhos de fartura e de vida confortável. Aportados estavam, mas a vida aqui seguia cheia de dificuldades e desafios.

Nas décadas seguintes, uma fração destes migrou às regiões norte e noroeste rio-grandense e ao oeste catarinense em busca de novas terras para reproduzir o modo de vida dos ancestrais e assegurar terra aos filhos. Essa enxamagem, conforme Roche, nos diferentes momentos, representou a expropriação da população autóctone, chamada cabocla, interditando-lhe seu processo de reprodução na condição camponesa; ao mesmo tempo, assegurou a daquele grupo de colonos. Estudar nesses dois processos com construção dos sítios simbólicos de pertencimento é o que intencionamos fazer.

As condições materiais de existência por si só não garantem o conjunto de valores de um sítio. É na relação dialética entre os valores, a cultura imaterial e os artefatos culturais que se constrói um sítio. Um dos autores a quem recorremos é Edward Thompson (1981), com a categoria experiência, gestada no embate com o estruturalismo de Althusser, quando introduz essa categoria. Dirá que as pessoas passam por guerras, prisões, e isso afeta a forma de pensar, o modo de vida, de ver o mundo. Ao se fazer referência a guerras, é necessário mencionar a Guerra do Contestado, que envolveu justamente a população cabocla da região em análise, considerada pelos historiadores a maior guerra camponesa da história, com estimativas de 20 mil mortos (MACHADO, 2004). Além dessa, a população já sofrera 
as consequências da Revolução Federalista, no Rio Grande do Sul, de 1893 a 1895, quando grandes contingentes migraram aos sertões que agora constitui o oeste catarinense.

A colonização, por sua vez, se expressa em um dos efeitos da enxamagem mencionada por Roche (1969), a categoria de experiência é vivida diferentemente pelos dois grupos. Aos caboclos representou o rompimento dos tempos (RENK, 2000); para os colonos, a busca de terras novas, férteis, com boas águas e matas frondosas. $\mathrm{O}$ inóspito e os enfrentamentos que tenham sido vivenciados no processo de ocupação das matas representavam a busca da Cocanha e das terras aos filhos dessas famílias. Aos caboclos significou a perda do paraíso idealizado, quando "tudo diferenciou", "quando tudo escasseou", quando perderam as terras, quando foram empurrados às áreas íngremes, para as barrancas dos rios, quando ficaram pequenos, quando uma nação de gente entrou e acabou com o mato, com os pinhões etc.

Diferentemente dos caboclos, os colonos sempre foram dotados de ethos de que a terra deveria ser legalizada, não bastava o registro em escritório, mas em cartório. Os caboclos, ágrafos, ao contrário, não confiavam nos papéis, tampouco nas cercas introduzidas pelos colonos. Entendiam que a terra era de Deus ou do Brasil e incompreensível a lógica de compra e venda. Paralelamente, toda a fala acerca de comida será no polo do passado, mencionada como riqueza e fartura e uma vida plena de saúde. Lembram-se das festas de outrora, como as de são Sebastião e do Divino Espírito Santo. As relações sociais são permeadas de ethos da solidariedade, as crenças do Monge João Maria, o catolicismo popular, as relações de compadrio, portadores de virtudes análogo ao que Thompson (1981) nomina de Economia Moral, ou seja, a terra não estava entre os bens previstos a serem vendidos. A venda de terras para os caboclos era uma transgressão às leis morais, análogo ao estudo por Polanyi (1980), em fato nominado Economia Substantiva, em outras circunstâncias históricas.

Paradoxalmente, décadas depois serão os filhos e netos de colonos que invocarão o princípio da Economia Moral, quando participam do Movimento dos Sem Terra (MST) e se insurgem contra a construção de hidrelétricas, organizados em torno do Movimento dos Atingidos pelas Barragens (MAB), arrancando os marcos fixados para delimitar a obra. Nestes movimentos, não sem tensões, aproximações entre os dois sítios começam a acontecer. Não é nosso objetivo analisar aqui a gênese e a trajetória do MST e outros movimentos sociais. Apenas o fazemos para ressaltar que tais movimentos incorporam valores dos dois sítios dos colonos e dos caboclos, aproximações estas que começam a ocorrer a partir do início dos anos de 1980 em lutas comuns - como pela reforma agrária -, por meio das quais se criam laços de confiança e de solidariedade 
nas inúmeras reuniões, eventos de formação, escolhas de lideranças, no convívio comum durante anos em acampamentos e, posteriormente, em assentamentos, nos quais colonos e caboclos têm que conviver nas mesmas comunidades.

Entretanto, tais tensões aparecem quando os assentamentos são feitos sem esse convívio anterior, no qual são selecionadas, por um lado, famílias de colonos ligados ao MST e, por outro, caboclos arregimentados pelas prefeituras ou pelo INCRA são assentados nos mesmos assentamentos que as famílias de colonos, sem negociações prévias. Nestes casos os distintos valores dos dois sítios afloram, muitas vezes de forma conflituosa, e as diferenças como o ethos e ritmos do trabalho, dos hábitos e costumes de organizar a propriedade, a moradia, de fazer a agricultura, de relações de solidariedade e confiança com os vizinhos e com as comunidades, dentre outras, produzem distanciamentos ${ }^{2}$.

\section{Experiência de colonização}

Centremo-nos na categoria experiência vivenciada por ambos os grupos, embora de forma e perspectivas diferenciadas. Recorrendo a Geertz (2004), diz o autor que a experiência é construída e as formas simbólicas nos termos dos quais ela é construída determinam sua organização própria.

Thompson (1981) afirma que muitas repetições do mesmo tipo de acontecimento ou acontecimentos inter-relacionados exercem influência sobre a consciência social. O historiador analisa relacionalmente a concepção de classe, entendendo que ela é feita e faz-se, em uma relação dialética. Em razão disso, enfrenta a ortodoxia marxista para os quais prevalece o determinismo econômico. Combate os grandes esquemas explicativos, tais como o modo de produção e o determinismo econômico.

Thompson (1981) assegura que pessoas não experimentam suas experiências apenas como ideias. Experimentam também como sentimentos e lidam com esses sentimentos na cultura, como normas, obrigações familiares, de parentesco, de reciprocidade, como valores ou na arte ou nas convicções religiosas (RENK, 1996).

A experiência de colonização foi radicalmente oposta para colonos e caboclos. Para os primeiros representou a possibilidade de uma ascensão, por maior que fossem a penúria e as dificuldades, no espaço social, obtendo terras e conquistando novas posições sociais. Aos caboclos representou o descenso social, a marginalização, a expulsão de suas terras, a diáspora cabocla, o não reconhecimento desse grupo social frente à Igreja Católica, à Escola e outros grupos sociais implantados com a colonização (RENK, 1996).

A perda das terras resultou na desestruturação de um modo de vida anterior dos caboclos, com a desorganização da base morfológica do grupo de posseiros, alterou os diversos níveis de vida desse grupo. São diferenças
2 Reflexões de um dos autores a partir de sua experiência de trabalho com assistência técnica e extensão rural aos assentamentos de Abelardo Luz entre os anos de 1987 a 1989. Na época, havia cinco assentamentos que tiveram origem nas históricas ocupações de 1985. Nestas áreas foram assentadas 580 famílias, e dois dos assentamentos eram compostos por famílias, em sua absoluta maioria, de caboclos, arregimentados pela prefeitura e pelo Incra, justamente por estarem entre as mais pobres do município e região. Nos demais assentamentos havia uma divisão entre os assentados que pertenciam e que não pertenciam ao MST, independentemente se fossem caboclos ou descendentes de colonos. Embora a divisão maior fosse entre quem pertencesse ou não ao MST, também eram perceptíveis as diferenças de valores entre colonos e caboclos em certos momentos, por exemplo, ao organizarem uma associação de compra de máquinas ou outras iniciativas que envolviam ação coletiva. 
de situações com elementos estruturais que permitem considerar a situação das colonizadoras no oeste catarinense como causadoras da crise de desenraizamento dos caboclos (RENK, 1996).

A abundância de terras permitia deslocamentos e escolha de novos lugares para moradia. Efetivamente a terra não era um bem raro, porque dispunham de áreas e de baixa concorrência, podendo mudar-se, se fosse o caso. A terra tornou-se mercadoria e bem raro com a colonização. As concepções de terra dessa população nos levam a Polanyi (1980), ao estudar sociedades chamadas arcaicas, nas quais a terra não consistia em mercadoria. Dos embates entre valores e práticas das sociedades arcaicas com os da sociedade de economia de mercado autorregulável, observa o autor: em $A$ Grande Transformação, que "a história e a etnografia conhecem várias espécies de economia” (POLANYI, 1980, p. 60). A Economia de Mercado é apenas uma delas, diferenciando:

Uma economia de mercado deve compreender todos os componentes da indústria, incluindo o trabalho, terra e dinheiro. [...] Acontece, porém, que o trabalho e a terra nada mais são do que os próprios seres humanos nos quais consistem todas as sociedades, e o ambiente natural no qual elas existem. Incluí-los no mecanismo de mercado significa subordinar a substância da própria sociedade às leis de mercado. [...] Terra é apenas outro nome para a natureza, que é produzida pelo homem. [...] A descrição do trabalho, da terra e do dinheiro como mercadorias é inteiramente fictícia. (POLANYI, 1980, p. 83-86).

Esse é o marco teórico da Economia Substantiva, sistematizada por Polanyi (1980), em oposição à economia formal ou de mercado, que movem o Moinho Satânico. Na Economia Substantiva, ao contrário da Economia Formal, um dos itens essenciais é o das relações humanas. As considerações de Polanyi (1980) na "grande transformação ocidental" das mercadorias fictícias em economia de mercado servem para comparar a entrada dos colonizadores com outro ethos de trabalho, de poupança e de economia, o que contribuiu para a expropriação do modo de vida peculiar dos caboclos.

A reconversão étnica dos caboclos, da condição de subalternidade ou de humanidade hierarquizada, para um espaço de visibilidade, na última década, tal quais outros grupos e o seu reconhecimento, acontece em ato de caráter formal, através da fundação da Associação Puxirão Caboclo. Foi criada, formalmente, em novembro de 2003, na Câmara de Vereadores de Chapecó, com diretoria, estatutos, prevendo a mais ampla inclusão, independentemente de credo religioso, partido político e gênero. Essa fundação procura ser politicamente correta, incluindo cotas para as mulheres na diretoria.

O passado é a matéria-prima sobre a qual se debruçam diferentes grupos para organizar, selecionar os fatos constitutivos da sua história. 
Halbwachs (1990) destaca que o passado é sempre reconstruído, de acordo com os conflitos, tensões, normas e problemáticas do presente.

Enfim, os colonizadores, os de origem, recorrerão ao período inicial da colonização para lembrar a dureza dos tempos iniciais, os perigos que a vida na selva oferecia, a dificuldade em derrubar o mato, a ausência de recursos médicos, religiosos, comércio, carência de alimentos, "ficar mais de mês sem comer pão", a necessidade feito virtude (BOURDIEU, 1979), ou as virtudes étnicas (SEYFERTH, 1992), como o ethos de trabalho, a autoexploração, com rede de sociabilidade, observando que esse lazer carrega um misto de trabalho, a exemplo dos filós ${ }^{3}$, os encontros noturnos sempre pautados no trabalho para não perder tempo.

Nos caboclos observa-se mais intensamente os vínculos que Polanyi (1980) aponta das relações que não estavam plenamente inseridas no mercado, com ritmo mais lento, acompanhado de cantorias que destoam e desprezam os valores do campesinato de origem e que internalizam a autoexploração, a intensidade da jornada de trabalho, o "não perder tempo", o babitus da poupança, da parcimônia, da cobrança e do rigorismo interno.

Colonos e caboclos, à sua maneira, como veremos adiante, desenvolviam suas atividades em uma economia familiar corporada (SHANIN, 1980). Nestas observa-se igualmente, citando Bouquet e Woortmann, que o campesinato se caracterizava por pequenas unidades familiares (RENK, 2000) e definia-se no trabalho familiar, na imbricação do parentesco e da economia, respaldada na hierarquia construída sob diferenças biológicas e cronológicas/etárias. É a partir dessas condições subjetivas e materiais que alicerçamos nosso sítio simbólico.

No quadro a seguir, buscamos sintetizar comparativamente os distintos valores dos dois sítios em análise.
3 O filó é um hábito social trazido pelos imigrantes da região italiana do Vêneto que se estabeleceram na região sul do Brasil. Constituía um encontro de famílias vizinhas, a partir do cair da noite, depois de finda a jornada de trabalho,e é hábito que praticamente deixou de existir. Tratava-se de um importante espaço de socialização e descontração, com a participação de toda a família.

Quadro 1 - Resumo comparativo dos valores fundadores do sítio dos colonos e dos caboclos

\begin{tabular}{|c|c|c|}
\hline & Colonos & Caboclos \\
\hline Origem étnica & $\begin{array}{l}\text { Imigrantes europeus (italianos, alemães } \\
\text { e poloneses) }\end{array}$ & $\begin{array}{l}\text { População preexistente à vinda dos colonos, } \\
\text { originária da miscigenação entre descendentes } \\
\text { de portugueses/espanhóis, ex-escravos e índios. }\end{array}$ \\
\hline Propriedade da terra & Formal (escritura) & $\begin{array}{c}\text { Posse (não viam necessidade de formalização } \\
\text { via escritura) }\end{array}$ \\
\hline Relação com o mercado & Forte & Inexpressiva \\
\hline Produção agropecuária & $\begin{array}{l}\text { Principalmente para o mercado. } \\
\text { Subsistência: trabalho feminino }\end{array}$ & Subsistência. Eventual venda do excedente \\
\hline Ethos do trabalho & $\begin{array}{l}\text { Trabalho como valor } \\
\text { fundamental da vida }\end{array}$ & Trabalho sem a preocupação da acumulação \\
\hline Relação com a natureza & $\begin{array}{l}\text { Natureza (florestas) como empecilho } \\
\text { ao desenvolvimento e transformada em } \\
\text { mercadoria (madeira) }\end{array}$ & Relação mais harmoniosa \\
\hline
\end{tabular}


A seguir descrevemos o processo tradicional de produção de alguns alimentos, com destaque aos valores presentes na sua produção, distribuição e consumo.

\section{O idioma da comida entre os caboclos}

Os caboclos remetem-se ao passado para qualificar sua comida como "comida de gente" em oposição à comida industrializada de hoje. "Comida de gente" é aquela que é feita em casa, com sabor artesanal. Muitos desses ingredientes ficam na memória, a exemplo da farinha de beiju, fabricada no monjolo. Outro preceito era cozinhar em panela de ferro, que fazia parte da vida natural e rústica de outrora.

$\mathrm{O}$ uso da banha suína, na panela de ferro, dava sabor especial à comida. A carne de porco, os torresmos ainda hoje são tidos como iguarias na mesa dos caboclos. Carne de porco pode ser consumida com mandioca cozida ou com quirera (trata-se de milho triturado e cozido com água). A banha é vista como um elemento étnico, já que alemães e italianos teriam incorporado azeite ou óleo. As representações dos caboclos explicitam que a longevidade cabocla dos ancestrais devia-se ao uso da banha que, além de alimento, tem elementos terapêuticos.

Nas festividades é comum que a carne de porco seja apreciada fria, isto é, assada no dia anterior. Em caso de dificuldade econômica, é frequente a compra de costela "raspada", ou seja, já retirada a maior parte da carne, a custo mais acessível, e preparada com a quirera ou a mandioca.

$\mathrm{O}$ pão nem sempre esteve presente na mesa do caboclo. $\mathrm{Na}$ maior parte das vezes o café da manhã consistia de virado de feijão, isto é, feijão, com banha, toucinho, com mistura para dar força ao trabalho pesado. Outro ingrediente apreciado na comida cabocla era a farinha de beiju e a farinha de mandioca, esta última fabricada nas atafonas.

Atualmente, há uma evidência do sítio simbólico do pertencimento caboclo que observamos nas festas religiosas, qualificadas de festas de resistência étnica. São elas a festa de São Sebastião e Festa do Divino Espírito Santo, chamadas festas de adoar em oposição às festas de pagar. A exemplo dos tempos de outrora, as festas de adoar não são festas para angariar recursos, ao contrário das festas costumeiras na região, como são as festas dos de origem. Ocorria uma coleta de produtos in natura para a festa; no dia de sua realização, todos compareciam e desfrutavam. $\mathrm{Ou}$ seja, as oferendas eram redistribuídas independentemente do montante de contribuição. Nas festas, segue-se a prática de oferecer a Mesada dos Inocentes, isto é, escolhem-se sete crianças, menores de sete anos, que são servidas por adultos, como forma de pagar promessa.

Outro ingrediente sempre lembrado na mesa cabocla é a presença da rapadura e do melado. Relato de viajantes informam que, no século retrasado, a população cabocla local tinha como prática costumeira a 
produção e o consumo de açúcar mascavo, a rapadura e o melado. Embora lembrados, têm diminuído nos tempos atuais.

\section{O idioma da comida entre os colonos}

Os produtos coloniais constituem-se em um conjunto de produtos que são - ou eram - produzidos ao longo do ano pelos colonos para o consumo familiar. Dentre estes estão os derivados do leite, em especial o queijo colonial; os derivados da carne suína, como banha, embutidos e defumados; e os panificados. Outros são de época, como os derivados da cana-de-açúcar (açúcar mascavo, chimias', melado, rapadura), produzidos no inverno, geralmente entre os meses de junho e julho, entressafra das lavouras. Ou os derivados de frutas de clima temperado, como doces e compotas de pêssego, de figo e de pera; e doces, geleias, sucos e vinho de uva. Ou, ainda, as conservas de pepinos, dentre outras hortaliças.

Dos derivados do leite são produzidos, sobretudo, o queijo colonial e a puina ${ }^{5}$. Já os descendentes de alemães, além do queijo colonial, produzem o kässchimier, um tipo de coalhada que é consumida no café da manhã, com pão e chimia.

Da carne suína é produzida uma ampla gama de produtos, com suas especificidades, a depender se de origem italiana ou alemã. $\mathrm{O}$ mais conhecido é o salame colonial. Mas há também o queijo de porco ${ }^{6}$ o sacol $^{7}$ e codeguin ${ }^{8}$. Entre os alemães, há alguns embutidos típicos, como linguiças cozidas na água antes de serem servidas e outras que, além da carne suína, recebem recheios especiais (arroz e algumas hortaliças), e que podem ser cozidas na água ou assadas antes se serem servidas. Estas últimas são tradicionalmente preparadas para ocasiões festivas, em especial para os $\operatorname{Kerbs}^{9}$, ainda frequentes naqueles municípios menores da região e de colonização predominantemente alemã ou em comunidades rurais.

Entre os panificados têm destaque o pão, as cucas ("cuca alta" entre os descendentes italianos, "cuca baixinha' e "cuca recheada com frutas" entre os descendentes de alemães), o strudel (típico alemão ou austríaco), as bolachas, grostolis ${ }^{10}$, e uma série de outros derivados da farinha, como os agnolines, tortéis, dentre outras massas.

Dos derivados da cana-de-açúcar, além do açúcar mascavo, destacase o melado e suas variações - melado batido, de tradição alemã, o "meladinho", as chimias feitas no tacho com frutas e hortaliças de época (laranja, abóbora, chuchu e mamão) e a cachaça. As compotas de frutas e conservas de hortaliças, doces de uva e de figo e o vinho colonial são comuns a ambas as etnias, embora a tradição de produção de doces, geleias, compotas de frutas de clima temperado, bem como de vinho e sucos de uva seja mais associada aos descendentes de italianos.
4 "Chimia" é um termo derivado do alemão "schimier" e designa doce em pasta, geralmente produzido a partir de frutas e açúcar mascavo.

5 Tipo de ricota produzida pelos descendentes de italianos.

6 Embutido feito de miúdos dos suínos (fígado, rins, coração) e as demais carnes menos nobres, como a da cabeça e torresmos moídos. Estas carnes, exceto o torresmo, são cozidas em água, após são trituradas, salgadas e temperadas com temperos verdes e pimenta do reino. A massa é, então, embutida no estômago do suíno e novamente cozida em água. Após o cozimento, este embutido permanece sob a ação de uma prensa de um dia para o outro para retirar o excesso de água e de gordura. Ao final do processo, o embutido fica com o formato de um “queijo", daí sua denominação.

7 Do dialeto vêneto, usado para designar copa.

8 Em italiano, codeghino ou coteghino. É também denominado pelos imigrantes do vêneto, por codeguin. Trata-se de um embutido feito com carne e pele suína, as quais, após cozidas em água fervente, são moídas e temperadas com sal, pimenta e especiarias. A massa temperada é, então, embutida em tripas finas. Antes de ir à mesa, o codeguin é cozido na água e servido quente com polenta, fortáia, radichi cotti e verduras, invariavelmente acompanhado de vinho tinto.

9 Kerbs significa quermesse em português. Trata-se de uma festividade típica alemã, de cunho religioso, que no Brasil são realizadas geralmente para comemorar o aniversário da inauguração da igreja da comunidade ou fundação município. Em geral, dura três dias. Inicia no sábado de tarde, com apresentações culturais, e continua à noite com baile, animado com bandinhas de música alemã, chopp e comidas típicas. O domingo, após o culto evangélico, é dedicado ao almoço entre as famílias, ocasião 
que os familiares e parentes de outras localidades e municípios se reúnem para confraternizar. $\mathrm{Na}$ segunda-feira, quando coincide com o feriado municipal, continua com apresentações culturais e encerra com outro baile típico.

10 Do dialeto vêneto, correspondendo à "cueca virada" em português.
Embora os produtos coloniais sejam predominantemente alimentos, há também o artesanato, como os chapéus e bolsas de tranças de palha de trigo. Assim, há um conjunto bastante amplo de produtos, os quais são associados ao modo de vida destes descendentes de imigrantes europeus que os diferenciam socialmente dos caboclos.

\section{O consumo dos produtos coloniais em eventos festivos}

Além de serem produzidos para o consumo das famílias dos agricultores, os produtos coloniais são também consumidos em uma série de eventos realizados na região, tais como Oktoberfests e Kerbs, festas e jantas italianas, cafés coloniais, festas do colono, ou outros eventos do gênero realizados nas cidades da região. Para ilustrar como tais produtos são apresentados e consumidos, fazemos a seguir uma breve descrição de duas destas festas. Uma delas é tipicamente baseada na culinária dos descentes de italianos. A segunda incorpora questões para além dos produtos coloniais, como o resgate e a valorização das sementes e mudas crioulas e os "produtos da roça” e da agroecologia.

\section{A Festa Colonial do Vinho, Queijo e Salame}

Realizada na cidade de Pinhalzinho, localizada a aproximadamente $40 \mathrm{~km}$ da cidade de Chapecó, a Festa Colonial do Vinho, do Queijo e do Salame é organizada anualmente pela prefeitura municipal e com forte apoio da cooperativa agropecuária e dos técnicos da Empresa de Pesquisa Agropecuária e Extensão Rural de Santa Catarina (Epagri). Embora a população de Pinhalzinho seja aproximadamente em igual proporção entre descendentes de alemães e italianos, a festa é tipicamente italiana.

A festa tem caráter regional, pois envolve também os municípios vizinhos, com participação de expositores e presença de lideranças políticas e da população das cidades próximas. Inicialmente o evento foi idealizado com o objetivo de divulgar os produtos coloniais e promover sua venda; porém, nas últimas edições, o caráter gastronômico e festivo tem prevalecido. Para a sua décima edição, realizada em 2010, o pavilhão foi decorado com motivos que fazem referência ao colono e seu modo de vida, em especial àqueles relacionados aos seus hábitos alimentares. Em um dos primeiros estandes de acesso ao pavilhão no qual ocorre a festa, o colono, neste caso o de origem italiana, é identificado pela sua cozinha e pelos alimentos típicos: ao lado do fogão à lenha com pedaços de polenta e salame sendo grelhados sobre a chapa e pendurados ao redor do fogão.

O momento mais aguardado e prestigiado é o "Jantar Típico Italiano". O sucesso do evento é avaliado pelos organizadores pelo número de pessoas 
presentes no jantar, que vem crescendo nas últimas edições, chegando a aproximadamente 1.800 convites vendidos na edição de 2010 .

O cardápio servido no bufê possui uma diversidade bastante grande de pratos. É basicamente composto por polenta preparada de diversas maneiras (polenta cozida, polenta cozida e temperada, polenta brustolada ${ }^{11}$ ), fortáia ${ }^{12}$, radicci cott $i^{13}$, diversos tipos de embutidos (salame, codeguin, queijo de porco, morcilha ${ }^{14}$ ), queijo colonial tradicional e envelhecido no bagaço da uva tinta ${ }^{15}$, diversos tipos de massa (vários tipos de macarrão, lasanha, tortéi $\left.{ }^{16}\right)$, carne de suína assada, frango assado e em molho, entre outros pratos, e uma grande diversidade de saladas. $\mathrm{O}$ vinho colonial (tinto e branco), além de refrigerantes e água, foram as únicas bebidas servidas no jantar - não se permitiu a venda de cerveja. Após o jantar houve um showe, em seguida, um baile, animado por bandas típicas italianas e alemãs.

A seguir descrevemos um evento festivo com caráter "híbrido", visto que, embora seja realizado em um município de colonização predominantemente de origem italiana e alemã, e envolva gastronomia, incorpora valores comuns no que diz respeito à crítica ao processo de industrialização da agricultura e perda de autonomia dos agricultores, como analisamos a seguir.

\section{A Festa dos Produtos da Roça e Festa Estadual da Pipoca, do Feijão e do Arroz colonial}

Como vimos anteriormente, a colonização foi o divisor de águas o entre mundo social dos dois grupos. No entanto, nos últimos anos um dos aspectos que aproxima colonos e caboclos é o tema ambiental. Os caboclos, de modo geral, sempre se consideravam mais ligados à natureza em oposição aos de origem, vistos como predadores. Na Associação Puxirão Cabocla, a agricultura, as sementes crioulas e os recursos fitoterápicos estão em sua pauta. O Movimento das Mulheres Camponesas, constituído por mulheres caboclas e de origem, tem uma agenda comum: a recuperação das sementes crioulas. O movimento de agricultura agroecológica, que se constrói em oposição à agricultura convencional, faz esforços para o plantio com sementes crioulas. Trata-se de um movimento de resistência, sabendo que será de menor produtividade em relação a outras sementes híbridas e transgênicas. São formas de marcar posição no mundo social.

No extremo oeste do estado, os movimentos sociais são bastante ativos. O movimento agroecológico é mais organizado que no restante da região, envolvendo um número significativo de agricultores e de técnicos, tanto do setor público como de ONGs. Essa vitalidade da agroecologia e a preocupação com o resgate e a revalorização dos produtos tradicionais ganha visibilidade pública via organização de eventos e festas. A de maior
11 "Brustolada" em dialeto do vêneto significa "sapecada". Trata-se de polenta fria cortada em pequenas fatias e grelhada na chapa do fogão à lenha ou em grelhas de ferro adaptadas para fogão a gás quando da ausência daquele.

12 Tipo de omelete, que leva no seu preparo, além de ovos, salame picado, queijo e temperos.

$13 \mathrm{Ou}$ radicci cozido, variedade de almeirão de folha estreita e amargo. Seu preparo consiste em cozinhá-lo na água; em seguida, é espremido para retirar o excesso de líquido, cortado finamente e refogado com temperos e pedaçinhos de salame frito.

14 A morcilha, ou morcela é um embutido, recheado com sangue (morcela preta), que é colhido no abate do animal, cozido e temperado com temperos verdes e especiarias e, então, embutido, geralmente nas tripas do próprio animal e depois cozidas em água fervente. Há também a morcilha branca, que resulta do excedente da produção do queijo de porco, que é então embutido em tripas.

15 Após a retirada do bagaço da uva do mosto para a produção de vinho tinto, os colonos de origem italiana tinham o costume de deixar algumas peças de queijo imersas neste bagaço durante alguns dias, método tradicional de conservação e que conferia também ao queijo uma cor escura e sabor bem característicos. Esta técnica era bastante utilizada pelos colonos para se obter um queijo com maior tempo de maturação. Entretanto, praticamente caiu no esquecimento devido ao quase desaparecimento dos parreirais, causados pela filoxera, praga de solo que praticamente dizimou os vinhedos da região a partir de meados do século passado. Durante a pesquisa de campo, observou-se que alguns produtores estavam retomando esta técnica de conservação do queijo.

16 Tipo de massa recheada com abóbora, queijo ralado, farinha 
de rosca, temperos verdes e nozmoscada ralada. Possui o formato de pastel, porém é cozido na água e temperado com molho de macarrão. expressão é a "Festa das Sementes Crioulas" realizada no município de Anchieta, extremo oeste do estado.

No município vizinho de Guaraciaba/SC foi colonizado majoritariamente por descendentes de italianos e alemães. Em maio de 2011, ocorreu a "3a Festa dos Produtos da Roça e a 1" Festa Estadual da Pipoca, do Feijão e do Arroz colonial”. Esta festividade faz parte do movimento maior associado, sobretudo, à agroecologia e ao resgate de variedades de sementes "crioulas" cultivadas tradicionalmente pelos agricultores da região e que envolve sementes e produtos também produzidos pelas populações caboclas e indígenas. Embora os produtos coloniais tenham um recorte étnico, neste caso produtos coloniais e agroecológicos se confundem, como pudemos observar tanto nos produtos expostos nos estandes pelos agricultores e suas organizações quanto nos eventos gastronômicos que fazem parte da programação do evento.

Essa aproximação entre a agroecologia e os produtos coloniais ficou também evidente na feijoada servida no almoço de sábado, prato com pouca tradição na região. Feita para aproximadamente 500 pessoas, todos os ingredientes foram produzidos agroecologicamente pelos agricultores do município, desde o feijão crioulo, passando pelos derivados de carne suína oriunda de agroindústrias familiares rurais e diversas variedades de arroz e demais acompanhamentos tradicionais, como couve, farofa e laranja. Porém, a feijoada sofreu importantes adaptações aos hábitos alimentares regionais. Assim, em lugar da tradicional caipirinha servida antes da feijoada e da cerveja que acompanha o prato, foi oferecido vinho colonial - ou suco para os que não bebiam bebida alcoólica. Entretanto, o vinho não era o único ingrediente pouco usual a ser servido com a feijoada. Também foram servidos polenta, carne em molho, diversos tipos de pães e cucas. Como sobremesa, os organizadores serviram diversos tipos de bolos, tortas e cucas, sagu de vinho e pudins. Assim, a festa aponta a capacidade reinventiva da composição dos elementos da tradição aliado aos novos ingredientes, ressignificados, como a dimensão da agroecologia enquanto sinônimo de resistência. Em um contexto em que a caipirinha não é usual do dia a dia nada mais simples que a lógica de a substituir pelo vinho, presente costumeiramente. Essa bricolagem dá o tom local de que uma feijoada não é sempre a mesma feijoada.

\section{Considerações finais}

A noção dos sítios simbólicos de pertencimento, no caso específico da região analisada, permitiu perceber os diferentes valores presentes nos sítios dos colonos e dos caboclos e captar sua dinâmica histórica, desde sua origem, quando os contornos entre ambos eram bastante nítidos, até o 
momento atual, em que buscam aproximações para fazer face às ameaças que pairam sobre ambos, causadas pela imposição de modelos econômicos e por padrões tecnológicos e produtivos que desconsideram os modos de vida, o saber-fazer e a relação que tais sítios estabelecem com a natureza.

Assim, a descrição dos sítios pelo idioma da comida (produção e consumo), permitiu perceber como ambos os sítios se aproximam e se apropriam dos movimentos pela ambientalização, via agroecologia/ produção de produtos coloniais, por exemplo, como resposta à exclusão devido à industrialização da agricultura.

Zaoual oferece recursos ao estudar o homo situs como animal territorial. Neste caso temos um território partilhado com duas territorialidades, marcadas por processos históricos distintos: a inclusão pela colonização para um grupo e a exclusão para outro grupo. A escolha do idioma da comida como fio condutor permitiu traçar o homo situs apontando as peculiaridades, a processualidade e os desdobramentos dos entrecruzamentos das histórias.

Dos recursos teóricos mantivemos diálogo com Bourdieu, em especial com a noção de habitus, que resulta na internalização da dimensão histórica nos grupos sociais e manifesta-se quando na dialética opus operatum e opus operandi, permitindo a compreensão das diferenças que norteiam grupos e indivíduos.

Embora Zaoual não tivesse elaborado categorias como Economia Moral e Experiência, entendemos que estas, brotadas em outros contextos, serviram-nos para tornar as leituras mais complexas e atuarem como ancoradouros aos sítios em estudo.

Acreditamos que na lógica da territorialidade, como apregoa Zaoual, e na de duas territorialidades, como nós expressamos, os caminhos, embora tenham sido inicialmente afastados, com o passar do tempo se cruzaram.

\section{Referências}

BOURDIEU, P. La Distinction. Critique sociale du jugement. Paris: Minuit, 1979.

BOURDIEU, P; SAYAD, A. Le Deracinement: la crise de l'agriculture traditionnelle em Algérie. Paris: Minuit, 1964.

DORIGON, C. Mercados de produtos coloniais da Região Oeste de Santa Catarina: em construção. 2008. 437 f. Tese (Doutorado em Engenharia de Produção) - Programa de Pós-Graduação em Engenharia de Produção, Universidade Federal do Rio de Janeiro, Rio de Janeiro, 2008.

DORIGON, C. et al. Produtos coloniais: tradição e mudança. Chapecó: Argos, 2015.

DORIGON, C.; RENK, A.Juventude rural, produtos coloniais e pluriatividade. Chapecó: Argos, 2013. 
DORIGON, C.; RENK, A. Técnicas e métodos tradicionais de processamento de produtos coloniais: de miudezas de colonos pobres aos mercados de qualidade diferenciada. Agricultura em São Paulo, v. 58, p. 101-113, 2011.

FRANCO, H. Cocanha: a história de um país imaginário. São Paulo: Companhia das Letras, 1998.

GEERTZ, C. O Saber Local: Novos ensaios em antropologia interpretativa. 7. ed. Tradução de Vera Mello Joscelyne. Petrópolis: Vozes, 2004.

HALBWACHS, M. Memória coletiva. São Paulo: Vértice, 1990.

HOBSBAWM, E.; RANGER, T. Introdução. In: HOBSBAWM, E.; RANGER, T. A invenção das tradições. Rio de Janeiro: Paz e Terra, 1984. p. 9-23,

LATOUCHE, S. L'approche culturelle: le site et la niche. In: LATOUCHE, S.; NOHRA, F.; ZAOUAL, H. Critique de la raison économique. Introduction à la théorie des sites symboliques. Paris: L'Harmattan, 1999. p. 59-78.

MACHADO, P. P. Lideranças do Contestado: a formação e a atuação das chefias caboclas. Campinas: Editorada da Unicamp, 2004.

MARTINS, J. de S. O Imaginário na imigração italiana. São Caetano do Sul: Fundação Pró-Memória de São Caetano do Sul, 2003.103 p.

PANHUYS, H. Do desenvolvimento global aos sítios locais: uma crítica metodológica à globalização. Trad. Michel Thiollent. Rio de Janeiro: E-papers, 2006. 145 p. Tradução de: La fin de l'occidentalisation du monde?: de l'unique au multiple.

POLANYI, K. A grande transformação. Rio de Janeiro: Campus, 1980.

RENK, A. A experiência em Thompson. História: Questões \& Debates, Curitiba, v. 13, n. 24, p. 78-104, jul./dez. 1996.

RENK, A. A luta da erva - um ofício étnico da nação brasileira. Chapecó: Argos, 1997.

RENK, A. Sociodicéia às avessas. Chapecó: Grifos, 2000. 440 p.

RENK, A.; SAVOLDI, A. Inventário da cultura imaterial cabocla no oeste de Santa Catarina. Chapecó: Argos, 2008.

ROCHE, J. A colonização alemã e o Rio Grande do Sul. Porto Alegre: Globo, 1969. 2 volumes.

SHANIN, T. A definição de camponês: conceituações e desconceituações: o velho e o novo em uma discussão marxista. São Paulo: Estudos Cebrap (26), 1980.

SEYFERTH, G. As contradições da liberdade: análise de representações sobre a identidade camponesa. Revista Brasileira de Ciências Sociais, v. 8, n. 7/8, p. 5760, fev. 1992.

THOMPSON, E. A miséria da teoria ou um planetário de erros: uma crítica ao pensamento de Althusser. Rio de Janeiro: Zahar, 1981.

ZAOUAL, H. Globalização e diversidade cultural. Textos selecionados e traduzidos por Michel Thiollent. São Paulo: Cortez, 2003. 
ZAOUAL, H. Nova economia das iniciativas locais: uma introdução ao pensamento pós-global. Tradução de Michel Thiollent. Rio de Janeiro: DP\&A: Consulado Geral da França/COOPE/UFRJ, 2006a. (Tradução de Nouvelle économie des initiatives locales).

ZAOUAL, H. Manegement situé et dévoloppement local. Paris: l'Harmattan, 2006b.

Submetido em: 06/07/2018

Aceito em: 01/11/2018 


\title{
LOS SITIOS SIMBÓLICOS DE PERTENENCIA DE LOS COLONOS Y DE LOS CABOCLOS DEL OESTE DE SANTA CATARINA
}

\begin{abstract}
Resumen
En cuanto a los hábitos alimentarios regionales y los contextos en que estos alimentos se producen y consumen, se busca en este texto problematizar el enfoque teórico de los sitios simbólicos de pertenencia, aún de poca circulación en Brasil. A partir de datos empíricos relacionados con los hábitos alimentarios y de las festividades organizadas en torno al consumo de alimentos originarios del saber hacer de los agricultores, se analiza la presencia en la región oeste de Santa Catarina de dos Sitios Simbólicos de Pertenencia. Uno de ellos formado por los descendientes de inmigrantes europeos (italianos, alemanes y polacos). El otro por los caboclos, población preexistente a la llegada de los colonos. Los caboclos fueron excluidos de sus tierras para dar lugar a aquellos. Se establecen comparaciones entre la noción de Sitio con otras nociones, en especial con la de habitus de Bourdieu y la de economía sustantiva de Karl Polanyi. Entre las conclusiones se subraya que la noción de sitios simbólicos de pertenencia ofrece recursos al estudiar el homo situs como animal territorial. En el caso analizado, se tiene un territorio compartido con dos territorialidades, marcadas por procesos históricos distintos, la inclusión por la colonización, para un grupo y la exclusión para otro grupo. La elección del idioma de la comida como hilo conductor permitió trazar el homo situs apuntando las peculiaridades, las procesualidades y los desdoblamientos de los entrecruzamientos de las historias.
\end{abstract}

Palabras clave: Sitio simbólico de pertenencia. Antropología de la alimentación. Productos coloniales. Comida cabocla.

\section{THE SYMBOLIC SITES OF BELONGING TO SETTLERS AND CABOCLOS OFTHE WEST OF SANTA CATARINA}

\begin{abstract}
Starting from the regional eating habits and the contexts in which such foods are produced and consumed, this paper seeks to problematize the theoretical approach of the Symbolic Sites of Belonging, which is still with little circulation in Brazil. Based on empirical data related to eating habits and festivities organized around the consumption of foods originating from farmer's know-how, it is analyzed the presence in the western region of Santa Catarina of two Symbolic Sites of Belonging. One of them is the descendants of European immigrants (Italians, Germans and Poles). The other by the caboclos, pre-existing population at the arrival of the settlers. The caboclos were excluded from their lands to give way to them. Comparisons between the notion of Sítio and other notions are made, especially with that of Bourdieu's habitus and that of Karl Polanyi's substantive economy. Among the conclusions it is emphasized that the notion of Symbolic Sites of Belonging offers resources when studying homo situs as a territorial animal. In the case analyzed, there is a shared territory with two territorialities, marked by distinct historical processes, inclusion by colonization, for one group and exclusion for another group. Choosing the language of food as the guiding thread allowed us to trace the homo situs pointing out the peculiarities, the processualities, and the unfolding of the intertwining of the stories.
\end{abstract}

Keywords: Symbolic site of belonging. Anthropology of food. Colonial products. Cabocla food. 